\title{
PROJETO GEROLEITE. MELHORA DA GESTÃO DA PRODUÇÃO LEITEIRA: CASO COOPERATIVA AGROPECUÁRIA DE MACAÉ-RJ*
}

\author{
GEROLEITE PROJECT. IMPROVEMENT ADMINISTRATIVE OF \\ DAIRY MILK PRODUCTION: COOPERATIVE MACAÉ-RJ CASE
}

\author{
Oliveira, C.A. ${ }^{\text {AA }}$, J.C.C. Almeida ${ }^{1 B}$, F.M. Pimentel ${ }^{2}$, P. Moraes $^{3}$ e C.C. Branco ${ }^{4}$ \\ 1'Z/UFRRJ. BR-465. km.07. CEP 23890-000. Seropédica. Rio de Janeiro. Brasil. Acao@ufrrj.br; ${ }^{\mathrm{B}}$ jcaravalho \\ ${ }^{2}$ SEBRAE/RJ. Av. Alberto Torres, 67. Campos. CEP 28010-117. Rio de Janeiro. Brasil. \\ fpimentel@sebraerj.com.br \\ ${ }^{3}$ SEBRAE/RJ. R.Télio Barreto, 318. Macaé. CEP 27910-060. Rio de Janeiro. Brasil. \\ ${ }^{4}$ Gero.Com Informatica Ltda. R. Yeda, 275. Teresopolis. Rio de Janeiro. Brasil. caxandi@gmail.com
}

\section{PALAVRAS CHAVE ADICIONAIS \\ Administração. Monitoramento. Custo de produção.}

\section{RESUMO}

O objetivo foi a coleta de dados no período de dezembro de 2001 a maio de 2002, no município de Macaé-RJ, com a participação inicial de 15 produtores cooperados da Cooperativa Agropecuária de Macaé, RJ, participando com plantel total de 1646 vacas, a fim de gerar relatórios como operacional e de performances, onde os produtores podiam tomar decisões de cunho administrativo. Foram emitidos 168 relatórios, com periodicidade mensal. Com o relatório operacional os produtores monitoravam a situação reprodutiva e produtiva de suas matrizes, e com o relatório de performances os seus índices zootécnicos e suas despesas, com ênfase no custo de produção mensal da leite. Através do custo de produção mensal, esperou-se que os produtores tomassem decisões voltadas à gestão de suas propriedades, dessa forma exigindo tecnologias que fossem capazes de reduzir seus custos. Os resultados mostraram que os produtores conseguiram nesse período, reduzir o custo médio do litro de leite em $0,3 \%$, redução média na despesa mensal da ordem de $2,5 \%$, redução na produção média mensal da ordem de $-0,6 \%$ e, incremento na produtividade por vaca/dia da ordem de $3,6 \%$.

*Projeto de Extensão Universitária UFRRJ. Financiado pelo SEBRAERJ, COAPEM, Prefeitura Municipal de Macaé e Produtores de leite.

Recibido:30-3-06. Aceptado: 10-6-08.

\section{ADDITIONAL KEYWORDS \\ Management. Tracing. Production cost.}

\section{SUMMARY}

The research was done between december 2001 and may 2002 in Macaé-RJ. This producers belonged to the Macaé Cooperated Producers, having 1646 cows. The work aimed to collect data for two reports, one operational and other of performance, where producers could take administrative decisions. During the research 168 monthly reports were done. Using the operational report, the producers monitored the reproductive and productive status of each cow and the performance report allowed to have the productive and finance indexes under control by the individual monthly production cost. By using the monthly real production cost, it was expected that producers could take decisions to improve the management of their properties, using technologies to reduce their real production costs. The results showed that was possible to reduce in $0.3 \%$ the cost per litre of milk, in $2.5 \%$ the total production cost. The monthly production not increased $-0.6 \%$ and cow productivity increased $3.6 \%$.

\section{INTRODUÇÃO}

O cooperativismo brasileiro, como destacou Freitas (2004), com 5,7 milhões de cooperados distribuídos em 7000 cooperativas de 13 ramos, entre eles a agropecuária, representava $6 \%$ do produto interno bruto, 
e com 200 mil empregos diretos. Segundo a Organização das Cooperativas Brasileiras, em 2003 havia no país 1587 cooperativas agropecuárias, com mais de 5 milhões de pessoas dependendo do processo econômico das mesmas. Protil (2002), em estudo exclusivo com cooperativas agropecuárias, observou que a estrutura organizacional das mesmas, formadas basicamente por não profissionais, como o fato responsável que levou estas organizações a perderem espaço em suas áreas de atuações. No caso específico da Cooperativa de Macaé as observações em seus balanços poderiam indicar possíveis problemas de insolvência, em seu processo como um todo. Castilha (2002) observou que o processo de insolvência é resultante da combinação de diferentes variáveis, algumas internas e outras externas. As de ordem interna classificada como: ineficiência de direção, estratégias errôneas, morosidade nas decisões, etc. assim como as de ordem externa, destacando a principal que é a não adequação as exigências do mercado, fato que pôde ser facilmente observado neste caso. Cruzio (1997) observou que as organizações cooperativas agropecuárias assemelham-se a empresas familiares, pois é comum ter um mesmo quadro diretivo mantendo-se à frente das organizações por um tempo prolongado, desconsiderando aspectos profissionais de seus dirigentes. Oliveira (2002) relatou que a produção brasileira de leite era representada por $90 \%$ de produtores com menos de 200 litros/dia, mesmo o grande produtor mostrou ao final do último século que também não suportava competir com os baixos preços praticados pelos processadores de leite.

O município de Macaé/RJ, já tinha longa tradição em pecuária leiteira, produção esta feita por produtores de variados portes (pequenos, médios e grandes), com média a baixa tecnologia de produção. A produção total diária do município em 2002 estava acima de 20 mil litros diários (IBGE, 2003), segundo a fonte oficial, existindo ainda os produtores que entregavam suas produções para processadores fora do município, portanto a produção total fugia das informações do leite sob controle oficial para este município.

O Projeto Geroleite desenvolveu tecnologia própria, inédita dentro dos processos de capacitação aos produtores leiteiros, em modelo que informava mensalmente quanto custou cada litro de leite produzido na propriedade e ao mesmo tempo disponibilizava aos produtores a situação zootécnica de suas matrizes, permitindo aos mesmos visualizarem as necessidades de adequações produtivas diante dos custos, tendo ferramentas operacionais à disposição.

Os resultados mensais, fossem eles zootécnicos e/ou financeiros, foram sempre comparados com as médias destes mesmos resultados dos últimos meses, desta forma, a cada mês da atividade foi possível a visualização das performances zootécnicas e financeiras dos últimos meses, independente do ano civil.

\section{MATERIAL E MÉTODOS}

O projeto Geroleite teve como base para processamento das informações, software desenvolvido especialmente para fins de confrontação de índices zootécnicos com as despesas mensais de uma propriedade leiteira em rotina mensal. O software foi desenvolvido em plataforma Access e Visual Basic, tendo a finalidade de uso restrito pelo gestor do grupo de produtores. A sistemática de coleta de dados foi realizada em nível de propriedade rural, utilizando um caderno com 377 páginas.

As informações coletadas em rotina diária foram: coberturas, parições, alimentos (volumes), medicamentos (custos), despesas com manutenção, produção de leite do dia e outros. As informações de rotina mensal foram consolidações das coberturas, parições, alimentos, medicamentos, manutenção, produção total de leite e outros. Coletadas também, despesas correlatas ao mês como: custos de mão de 


\section{MELHORA DA GESTÃO DA PRODUÇÃO LEITEIRA}

obra, assistência técnica, luz e telefone, aquisições fixas e semifixas e controle leiteiro.

Além das informações tradicionais cadastrais, foram anotados os valores patrimoniais dos investimentos fixos e semifixos envolvidos na propriedade. Sendo também cadastradas todas as vacas e reprodutores do grupo, em um total de 1646 vacas e 64 reprodutores.

As informações consolidadas foram imediatamente transmitidas por e.mail para a base do projeto Geroleite, no Instituto de Zootecnia da UFRRJ, passando a gerar dois tipos de relatórios por produtor; relatório de monitoramento e de performances.

No relatório de monitoramento, foram informados os dados e índices zootécnicos de cada matriz, como: idade, produção média dos controles leiteiros, dias em lactação, intervalo de partos, período de serviço, período seco e datas reprodutivas. No relatório de performance foram informadas a composição do rebanho e as respectivas unidades animal (UA), dados e índices zootécnicos do rebanho como: natalidade, fertilidade, período de serviço, intervalo de partos, idade média do rebanho, tempo médio de lactação das matrizes, produtividade média do último controle leiteiro, produção de leite total no dia do controle, litros por hectare e custo de um litro de leite no mês do controle.

Na parte financeira, foram demonstrados as despesas mensais com medicamentos, manutenção, mão de obra acrescida de $80 \%$ de leis sociais, assistência técnica, luz e telefone, outros, depreciações e despesas com alimentos, que foram divididos conforme o uso de cada produtor nas seguintes possibilidades; concentrados, cana, capim picado, sal mineral, silagem, feno, polpa cítrica, cevada e sorgo.

Este relatório também apresentava três gráficos; produtividade leiteira (média/litros/vaca), produção de leite (litros/dia do controle) e custo por litro de leite mês ( $\mathrm{R}^{*}$ ),

$* 1 \mathrm{US} \$=\mathrm{R} \$ 2,36$. acumulando os desempenhos mensais Mensalmente foram realizados encontros na sede da cooperativa, entre os produtores, o técnico de campo e os gestores do projeto Geroleite, onde foram analisados e discutidos os resultados.

\section{RESULTADOSEDISCUSSÃO}

Para fins de análise geral dos resultados foram considerados os parâmetros financeiros: redução do custo do litro de leite e na despesa mensal e técnicos: incremento na produção de leite e na produtividade leiteira.

\section{REduÇÃOdo CUSTOdOLITROdE LEITE}

O grupo obteve como resultado médio a redução de $0,3 \%$ no custo da leite, sendo que 7 produtores com reduções superiores a $40 \%$ e 7 com acréscimos superiores a $40 \%$. $\mathrm{Na}$ realidade o projeto por ter operado em apenas 6 meses ou metade de um ciclo pecuário, não pode fazer avaliação adequada, a principal conclusão é que o período analisado se deu por todo o verão e início do inverno, onde se pode destacar que os produtores que tinham no modelo de semiconfinamento, com partos direcionados para a entressafra, conseguiram aumentar seus custos no momento em que a natureza está favorável a produção.

\section{ReduÇÃOnADESPESAMENSAL}

O grupo obteve como resultado médio redução de $2,5 \%$ nas despesas, destacando o caso de um produtor que obteve redução de custo unitário acima de $10 \%$, apesar da elevação das despesas superior a $50 \%$, podendo ser observado caso oposto, onde o produtor preferiu cortar despesas mensais, acabando por elevar seu custo unitário.

\section{INCREMENTO NAPRODUÇÃO DE LEITE}

$O$ grupo obteve redução média na produção de leite de $-0,6 \%$, com 9 produtores acima da média e com incrementos e outros 5 com reduções. O destaque foi para a diminuição de produção de alguns produtores, onde o objetivo foi de alcançar 
patamar econômico, já que a maioria deles operavam sob intenso uso de alimentação concentrada e a partir destes controles foram capazes de monitorar resultados e verificarem a relação benefício custo desfavorável.

\section{INCREMENTONA PRODUTIVIDADE}

$\mathrm{O}$ grupo obteve incremento médio na produtividade da ordem de $3,6 \%$, com apenas 4 produtores acima da média, sendo possível notar a partir dos relatórios, que suas produtividades eram artificializadas ou sem base econômico sustentável. Podendo destacar que o produtor que obteve a maior redução no custo unitário, obteve incremento de produtividade dentro da média, desta forma solidificando seu posicionamento produtivo com base no gerenciamento de custos, onde o mesmo conseguiu cortar despesas que eram desnecessárias e não influenciavam de forma positiva seus resultados produtivos.

A tabela I, apresenta os resultados sob o aspecto dos custos de produção.

\section{CONCLUSÕES}

O objetivo do projeto não foi perfeita-

\section{BIBLIOGRAFIA}

Castilha, J.S. 2002. Uma contribuição a análise de demonstrativos contábeis através de modelos de previsão de insolvência: O caso específico de cooperativas agropecuárias. Em: XVI Congresso Brasileiro de Contabilidade. Disponível em: <www.cfc.org.br>. Acesso em: 14/03/2005.

Cruzio, H.O. 1997. Como organizar e administrar uma cooperativa. $1^{a}$ ed. Editora Fundação Getúlio Vargas. São Paulo.

Freitas. M.L. 2004. Cooperativismo e globalização. Disponível em: <www.paginarural.com.br> Acesso em: 18/03/2005.

IBGE. 2003. Produção da pecuária municipal. PPM.
Tabla I. Resultado geral do parâmetro custo de produção de 1 litro de leite para os participantes do projeto Geroleite (dezembro de 2001 a maio de 2002). (Overall outcome for the parameter production cost of 1 liter of milk for Geroleite project participants (December 2001 to May 2002)).

\begin{tabular}{lcc}
\hline Maio 2002 & $\mathrm{R} \$$ & US\$ \\
\hline Média & 0,47 & 0,19 \\
Menor & 0,20 & 0,08 \\
Maior & 0,68 & 0,28 \\
\hline
\end{tabular}

mente cumprido, devido ao prazo estabelecido de 12 meses, ou um ciclo pecuário, não ter sido cumprido por problemas econômicos e financeiros da cooperativa.

No caso específico dos produtores analisados, houve alguns ganhos diretos, principalmente com relação a monitoramento do benefício custo.

$\mathrm{O}$ aspecto do monitoramento mensal foi condição fundamental para a obtenção de resultados, manutenção dos produtores em patamares produtivos com sustentabilidade e possibilitou a gestão do negócio leiteiro em bases precisas.

Instituto Brasileiro de Geografia e Estatística Disponível em: <www.ibge.com.br>. Acesso em: 14/03/2005.

Oliveira, A.C. 2002. Produto Geroleite: Descrição de uma metodologia para apoiar a gestão técnica e financeira do pecuarista leiteiro. $43 \mathrm{p}$. Dissertação (Mestrado Gestão de Negócios). Universidade Federal Rural do Rio de Janeiro. Seropédica.

Protil, R.M. 2002. Gestão da tecnologia da informação em cooperativas agropecuárias. Em: Agrosoft 2002. Brasília. Disponível em: <www.agrosoft.com>. Acesso em: 22/03/2005. 